\title{
Oxidic or metallic palladium - which is the active phase in Pd-catalysed aerobic alcohol oxidation?
}

\author{
Jan-Dierk Grunwaldt*, Matteo Caravati, and Alfons Baiker \\ Institute of Chemical and Bioengineering, Department of Chemistry and Applied \\ Biosciences, ETH Zurich, Hönggerberg - HCI, CH-8093 Zurich, Switzerland
}

\section{Electronic support information}

The electronic support information gives further details on the in situ setup for the combined investigation of the catalyst structure by EXAFS and of the catalytic activity by on-line FTIR.

\section{Details on the experimental setup for combined XAS and IR measurements}

The in situ experiments were conducted in a continuous-flow spectroscopic cell (reaction cell) that contained the sieved catalyst and is suited for structural investigations by X-ray absorption spectroscopy. The outlet of the reaction cell was connected to a flow-through IR transmission cell facilitating on-line determination of the catalytic activity. This combination allows the simultaneous monitoring of the structure by XAS and the catalytic activity by IR spectroscopy and thus to derive structure-performance relationships.

The reaction cell (volume ca. $1 \mathrm{ml}$ ) was located in an oven and was fixed on an $x, z, \theta$ table to allow positioning in the beam. The X-rays passed through the reaction cell via Xray transmitting windows (i.e. Al-foil, Kapton ${ }^{\circledR}$ ) and the pathlength of the x-rays through the cell amounted to $5 \mathrm{~mm}$ in case of energies around the Pd K-edge. A similar design has been described in refs [1,2] and will be described in detail in ref. [3]. 
The flow-through transmission cell for on-line product analysis by IR spectroscopy was home-made, it was equipped with $\mathrm{CaF}_{2}$-windows, and the pathlength of the probing beam through the cell was of $1 \mathrm{~mm}$. The cell was placed in a Tensor 27 infrared spectrometer (Bruker Optics, Germany) with DTGS detector. Typically, the IR spectra were taken every $30 \mathrm{~s}$ ( $28 \mathrm{scans}, 4 \mathrm{~cm}^{-1}$ resolution, range $\left.400-4000 \mathrm{~cm}^{-1}\right)$.

A closed system was used where all gas-out lines were connected to the exhaust system. The reaction mixture (200 $\mu$ l benzyl alcohol in cyclohexane) was stored in two separate glass bubble tanks, where the liquid could be saturated with $\mathrm{Ar}$ or $\mathrm{O}_{2}$ at 1 bar. The third tank contained pure cyclohexane saturated with $\mathrm{He}, \mathrm{O}_{2}$ or $\mathrm{H}_{2}$. Liquids were provided from the tanks to the reactor or through a by-pass to the purging collector vessel by a peristaltic pump (ISMATEC Reglo 100) put in front of the reactor. The flow rate was $0.68 \mathrm{ml} \mathrm{min}^{-1}$ except for oxygen-saturated cyclohexane. The joints and tubes transferring oxygen-free medium were made of stainless steel in order to avoid oxygen diffusion into the feed.

\section{X-ray absorption spectroscopy}

XAS spectra were recorded in the transmission geometry at HASYLAB, DESY (Hamburg, Germany) at beamline X1 with the use of a $\mathrm{Si}(311)$ double crystal monochromator. The storage ring was operated at $4.45 \mathrm{GeV}$ with injection currents of $150 \mathrm{~mA}$. Higher harmonics were removed by detuning the crystals to $60 \%$ of the maximum intensity. For recording the intensity of the incident and the transmitted Xrays, three ionization chambers, filled with $\mathrm{Ar}$ and $\mathrm{Kr}$, respectively, were used. The 
samples were located between the first and second ionization chamber, a reference sample (Pd-foil) was placed between the second and the third ionization chamber.

EXAFS spectra of the as prepared catalyst placed in the flow cell, and under stationary reaction conditions during the in situ experiments, were taken in the stepscanning mode around the Pd K-edge $(24.350 \mathrm{keV})$ between 24.10 and $25.50 \mathrm{keV}$ (typically $40 \mathrm{~min} / \mathrm{scan}$ ). During in situ studies under dynamic reaction conditions, faster scans between 24.32 and $24.5 \mathrm{keV}$ were recorded in the step scanning mode or by applying the continuous scanning mode (typically $5 \mathrm{~min} / \mathrm{scan}$ ).

The raw data were energy calibrated (Pd-foil: $24.350 \mathrm{keV}$, first inflection point), background corrected and normalized using the Athena 0.8.049 software [4] and according to typical procedures described in ref. $[5,6]$. Fourier transformation for EXAFS data was applied to the $\mathrm{k}^{3}$-weighted functions in the interval $\mathrm{k}=2-12.8 \AA^{-1}$. Data fitting was performed in R-space using theoretical backscattering phases and amplitudes calculated with the ab initio multiple scattering code FEFF6.0 [7].

\section{Examples for on-line FTIR-spectra and the full set of XAS and catalytic data}

Figures S1 and S2 show typical spectra in the carbonyl stretching and C-O stretching regions. In both cases a clear change in the carbonyl stretching region was observed after reduction of the Pd-catalyst. Product analysis by GC confirmed the presence of benzaldehyde after reduction.

The spectra as shown in Figures S1 and S2 were used to determine the relative catalytic activity in both experiments as described in the publication (Figs. 1 and 2) and in the support information (Figs. S3 and S4). 


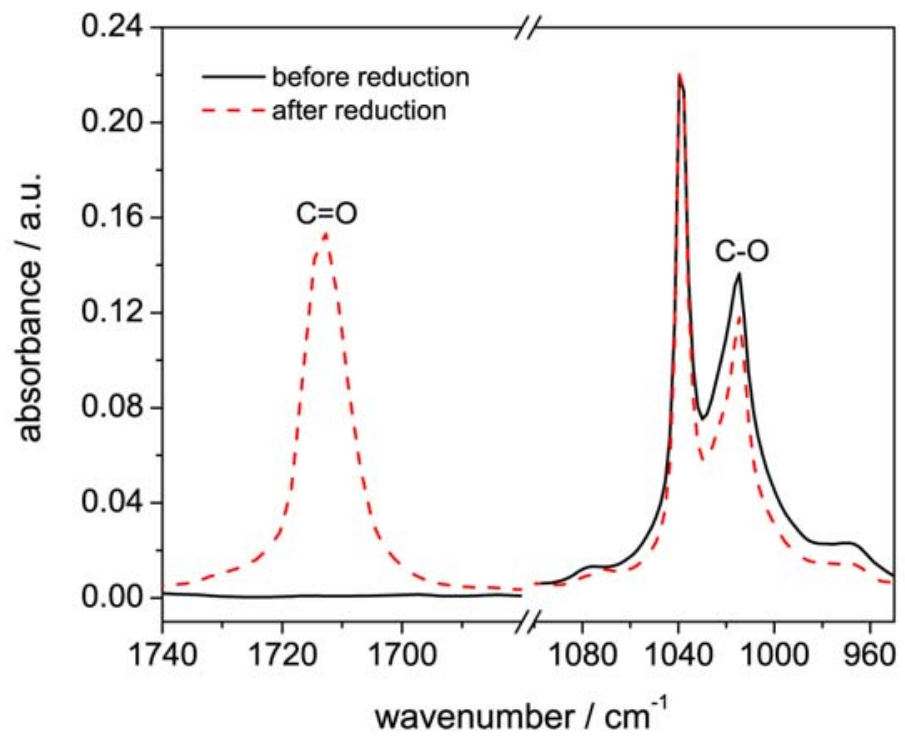

Figure S1: IR-spectra of the reaction mixture at the outlet of the reaction cell containing the $5 \mathrm{wt} \% \mathrm{Pd} / \mathrm{Al}_{2} \mathrm{O}_{3}$ catalyst, before and after reduction in hydrogen.

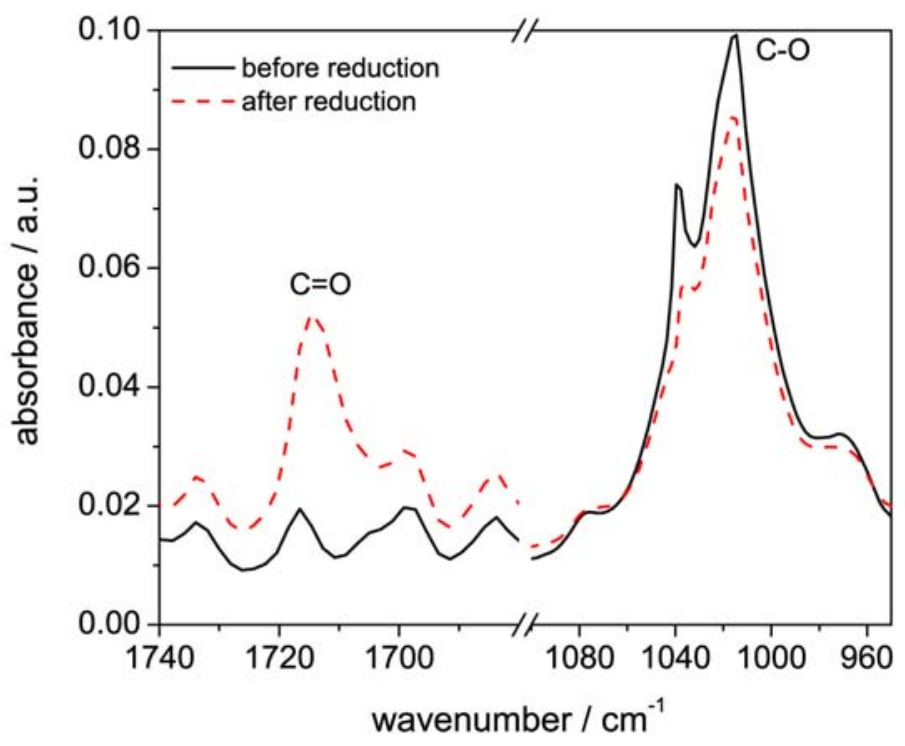

Figure S2: IR-spectra of the reaction mixture at the outlet of the reaction cell containing the $0.5 \mathrm{wt} \% \mathrm{Pd} / \mathrm{Al}_{2} \mathrm{O}_{3}$ catalyst, before and after reduction in hydrogen. 

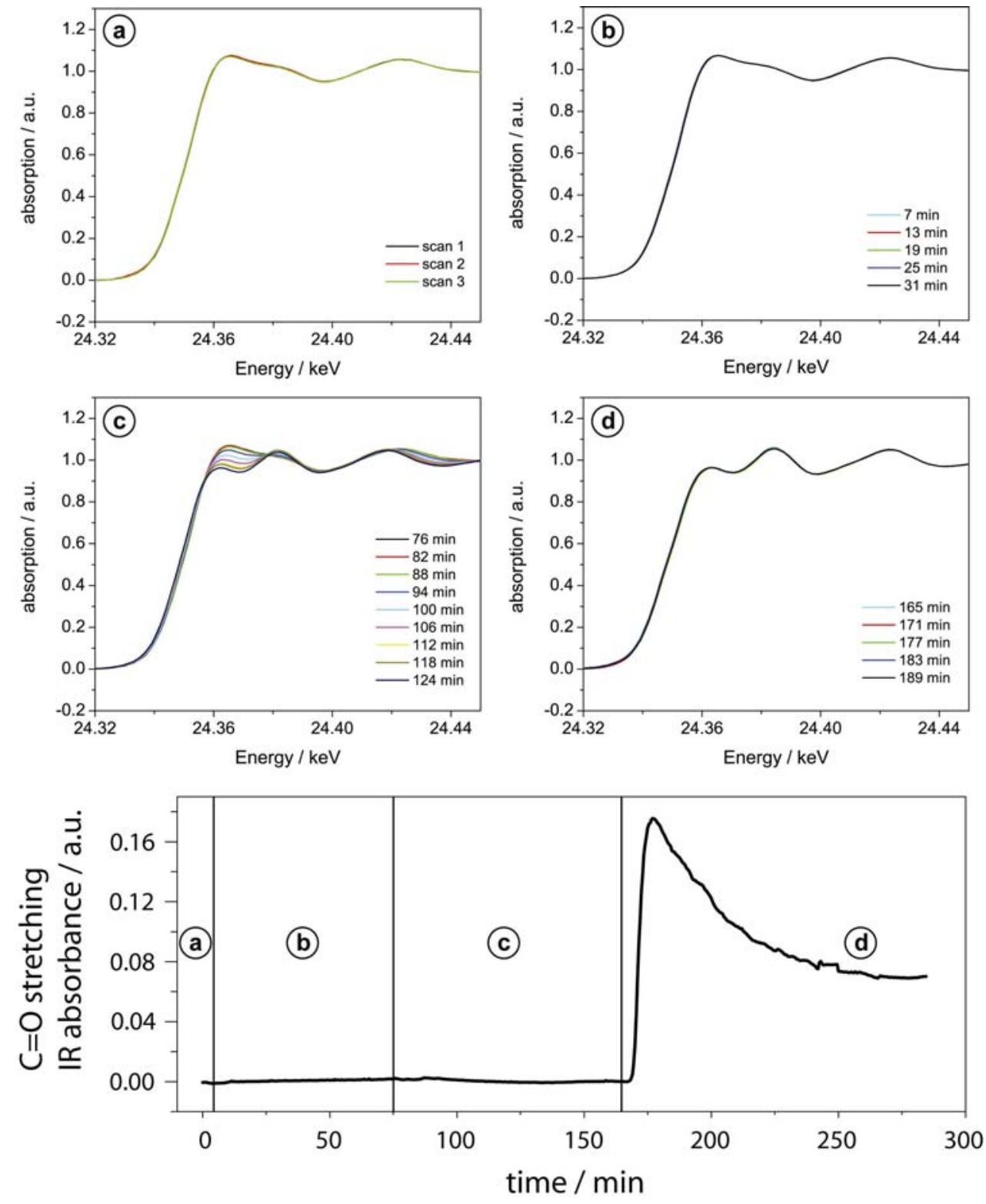

Figure S3: In situ X-ray absorption spectra of $5 \% \mathrm{Pd} / \mathrm{Al}_{2} \mathrm{O}_{3}(40 \mathrm{mg})$ during the selective oxidation of benzyl alcohol and the relative catalytic activity measured on-line by determining the absorption of the $\mathrm{C}=\mathrm{O}$ stretching band at different steps of the reaction: (a) the as-received catalyst in cyclohexane at $50{ }^{\circ} \mathrm{C}$; (b) catalyst in benzyl alcohol $/ \mathrm{O}_{2} /$ cyclohexane at $50{ }^{\circ} \mathrm{C}$; (c) during reduction in $\mathrm{H}_{2} /$ cyclohexane at $50{ }^{\circ} \mathrm{C}$; (d) catalyst in benzyl alcohol $/ \mathrm{O}_{2} /$ cyclohexane at $50{ }^{\circ} \mathrm{C}$; the benzyl alcohol/cyclohexane solutions and pure cyclohexane were saturated with oxygen and hydrogen, respectively; the concentration of benzyl alcohol was $200 \mu \mathrm{l} / 100 \mathrm{ml}$ cyclohexane; (corresponds to Figure 1 in the publication). 

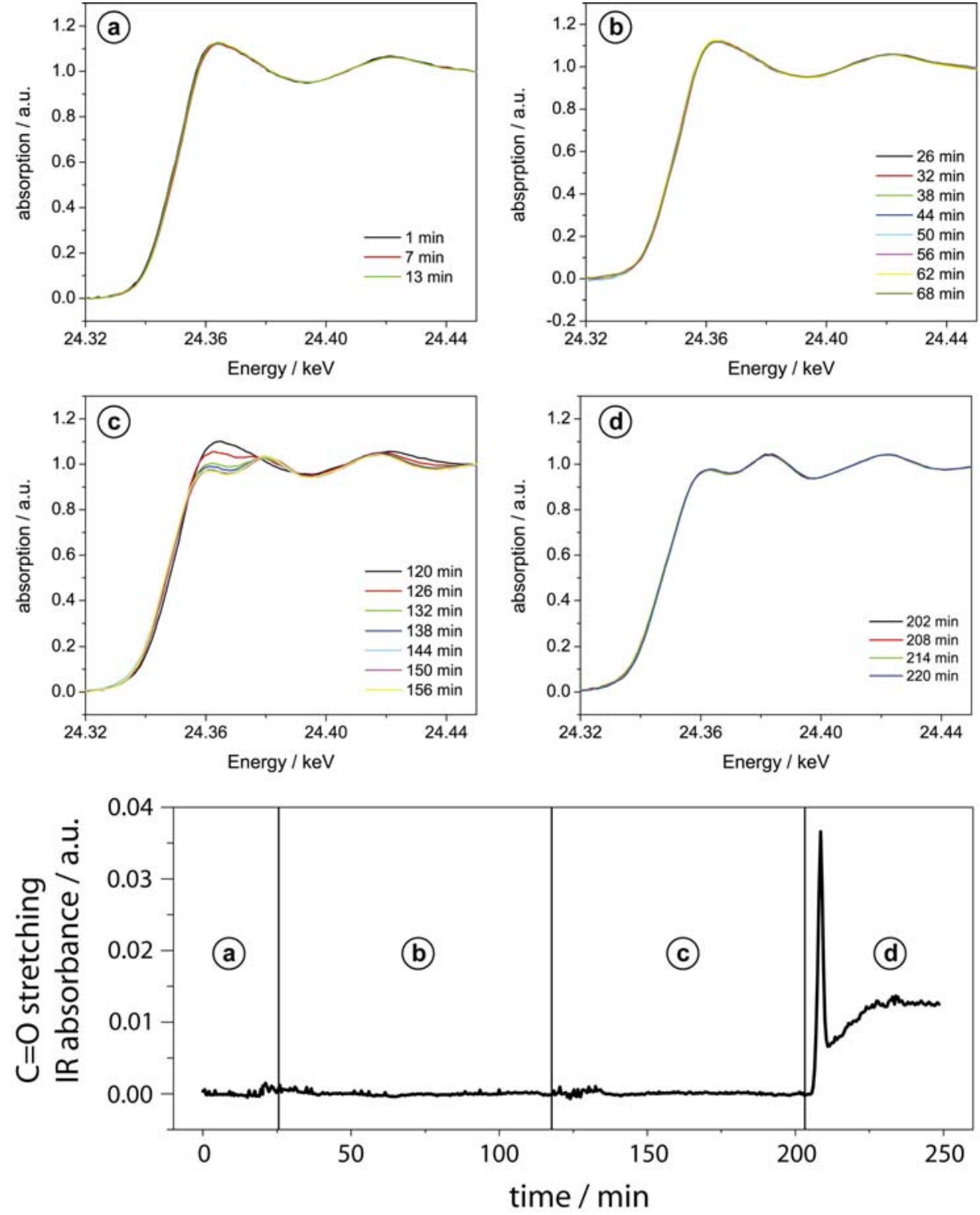

Figure S4: In situ X-ray absorption spectra of $0.5 \% \mathrm{Pd} / \mathrm{Al}_{2} \mathrm{O}_{3}$ (shell impregnated, sieved fraction $200 \mu \mathrm{m}<\mathrm{d}<300 \mu \mathrm{m}$ ) during the selective benzyl alcohol oxidation and the relative catalytic activity using the absorption at the $\mathrm{C}=\mathrm{O}$ stretching band at different steps of the reaction: (a) the as-received catalyst in cyclohexane at $50{ }^{\circ} \mathrm{C}$; (b) catalyst in benzyl alcohol $/ \mathrm{O}_{2} /$ cyclohexane at $50{ }^{\circ} \mathrm{C}$; (c) during reduction in $\mathrm{H}_{2} /$ cyclohexane at $50{ }^{\circ} \mathrm{C}$; (d) catalyst in benzyl alcohol $/ \mathrm{O}_{2} /$ cyclohexane at $50{ }^{\circ} \mathrm{C}$; the benzyl alcohol/cyclohexane solutions and pure cyclohexane were saturated with oxygen and hydrogen, respectively, the concentration of benzyl alcohol was $200 \mu \mathrm{l} / 100 \mathrm{ml}$ cyclohexane. 

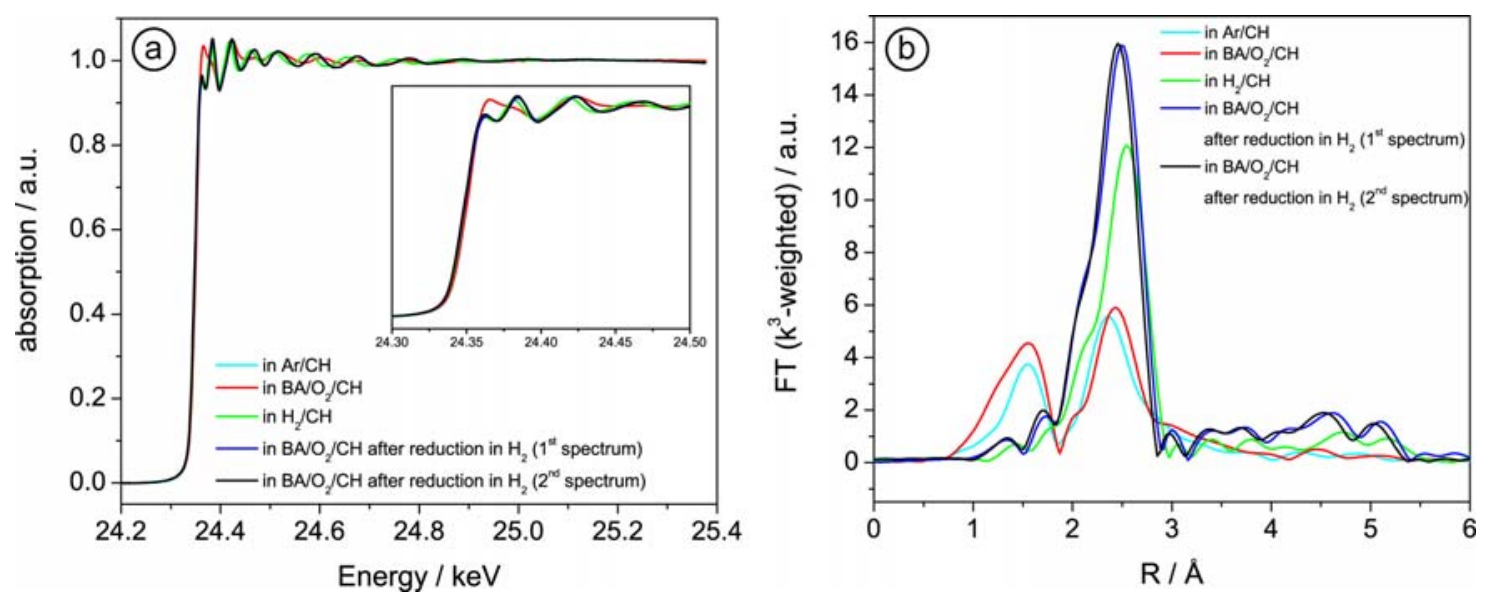

Figure S5: In situ EXAFS spectra (a) and the corresponding Fourier transformed data (b) of $5 \% \mathrm{Pd} / \mathrm{Al}_{2} \mathrm{O}_{3}$ during the different steps of the selective benzyl alcohol oxidation (corresponds to Figure 2 in the publication).
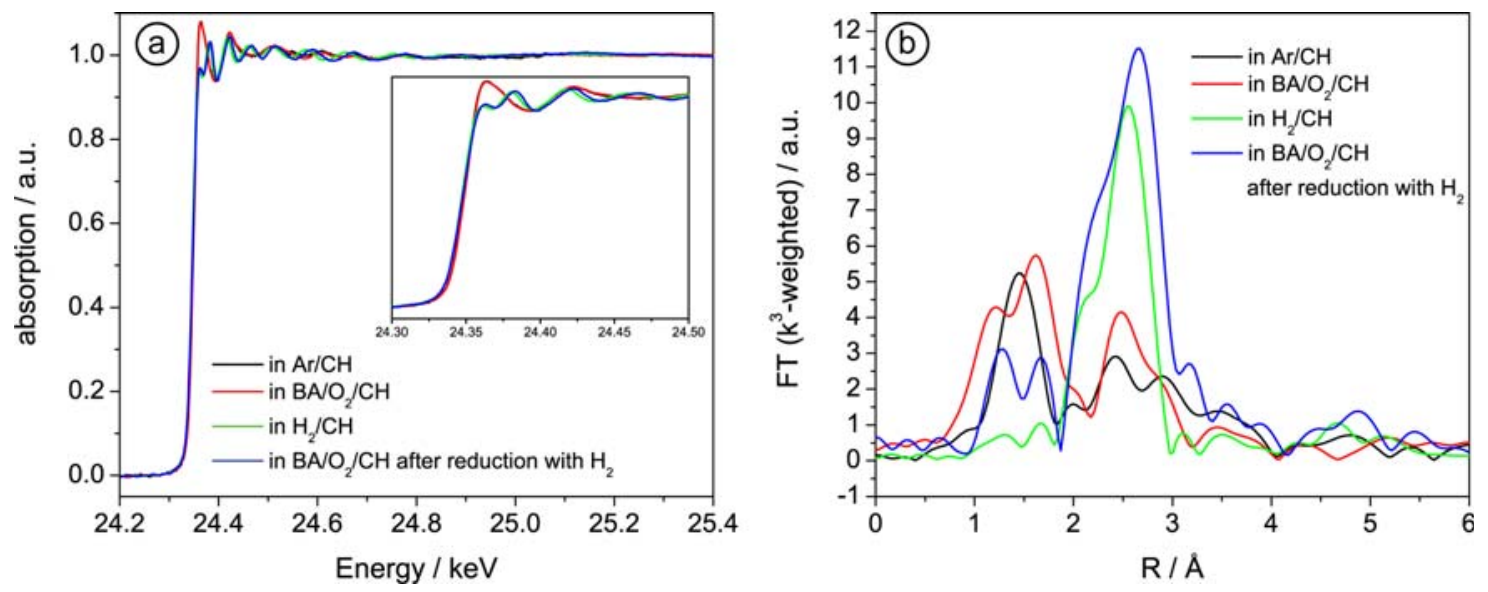

Figure S6: In situ EXAFS spectra (a) and the corresponding Fourier transformed data (b) of $0.5 \% \mathrm{Pd} / \mathrm{Al}_{2} \mathrm{O}_{3}$ during the different steps of the selective benzyl alcohol oxidation.

\section{References:}

[1] J.-D. Grunwaldt, C. Keresszegi, T. Mallat and A. Baiker, J. Catal. 2003, 213, 291.

[2] C. Keresszegi, J.-D. Grunwaldt, T. Mallat and A. Baiker, J. Catal. 2004, 222, 268.

[3] C. Mondelli, D. Ferri, J.-D. Grunwaldt, S. Mangold, and A. Baiker, in preparation.

[4] B. Ravel and M. Newville, J. Synchrotron Rad. 2005 12, 537.

[5] B. K. Theo, EXAFS: Basic Principles and Data Analysis, Springer, Berlin, 1986.

[6] D. C. Koningsberger and R. Prins, X-ray Absorption: Principles, Applications, Techniques of EXAFS, SEXAFS, and XANES, Wiley, New York, 1988.

[7] S. I. Zabinsky, J. J. Rehr, A. Ankudinov, R. C. Albers and M. J. Eller, Phys. Rev. B 1995, 52, 2995. 
